\title{
VARIETAL VARIATION IN STOMATAL CONDUCTANCE, TRANSPIRATION AND PHOTOSYNTHESIS OF COMMERCIAL SUGARCANE VARIETIES UNDER TWO CON- TRASTING WATER REGIMES
}

\author{
ALC De Silva ${ }^{1 *}$ and WAJM De Costa ${ }^{2}$ \\ ${ }^{1}$ Division of Agronomy, Sugarcane Research Institute of Sri Lanka, Uda Walawe \\ ${ }^{2}$ Department of Crop Science, Faculty of Agriculture, University of Peradeniya, Peradeniya, Sri Lanka
}

Accepted: $6^{\text {th }}$ October 2009

\begin{abstract}
The study was conducted to evaluate some physiological characters of commercial sugarcane varieties under different growing conditions in Sri Lanka. A field experiment was conducted at the Sugarcane Research Institute, Uda Walawe $\left(6^{\circ} 21^{\prime} \mathrm{N}\right.$ latitude, $8^{\circ} 48$ ' $\mathrm{E}$ longitude and $76 \mathrm{~m}$ altitude) using eight sugarcane (Saccharum hybrid L.) varieties grown under irrigated and rainfed conditions in a split plot design. Stomatal conductance $\left(g_{s}\right)$, instantaneous transpiration rate $\left(E_{l}\right)$ and photosynthetic rate per unit leaf area $\left(P_{n}\right)$ were measured. Canopy stomatal conductance $\left(g_{c}\right)$, instantaneous canopy transpiration rate $\left(E_{c}\right)$ and transpiration efficiency $\left(P_{n} / E_{l}\right)$ was calculated. The behaviour of $g_{s}$ in many respects to the moisture availability and growing stage was similar to the responses seen in $\boldsymbol{P}_{n}$. Water deficit significantly reduced $g_{s}, E_{1}$ and $\boldsymbol{P}_{n}$. Recovery of $g_{s}$ and $\boldsymbol{P}_{n}$ from water stress with rainfall was quite rapid under rainfed conditions. The varieties Co775, SL8306, SL7103 and SL88116 which had higher $P_{n}$ and $P_{n} /$ $E_{l}$, and lower $g_{s}, E_{l}, g_{c}$ and $E_{c}$ showed comparatively superior physiological performances under rainfed conditions. Water conservation through lowering stomatal conductance, both at the individual leaf and canopy level, and higher photosynthetic rate were identified as some physiological mechanisms responsible for drought tolerance of sugarcane.
\end{abstract}

Key words: Sugarcane, Stomatal conductance, Transpiration, Photosynthesis, Water regimes

\section{INTRODUCTION}

Sugarcane is one of the extreme types $C_{4}$ plant and it can have extraordinarily high rates of $P_{n}$, found in crop plants (Irvine 1967; 1975 and 1983). Moreover, $P_{n}$ of sugarcane does not show light saturation even at full sunlight because of their $\mathrm{CO}_{2}$ concentrating mechanism. Therefore, even under optimum conditions, the stomatal conductance $\left(g_{s}\right)$ of sugarcane is lower than that of the $C_{3}$ crops. Therefore, sugarcane could maintain a higher rate of $P_{n}$ under full sunlight with lower rates of canopy transpiration rate $\left(E_{c}\right)$ to increase the water use efficiency (De Costa 2000). The light saturated maximum $P_{n}$ in commercial varieties of sugarcane ranges from 31 to $53 \mu \mathrm{mol} \mathrm{CO}_{2} \mathrm{~m}^{-2} \mathrm{~s}^{-1}$ (Irvine 1967 and Roberts et al. 1990). Moreover, it is at a maximum during the grand growth stage and tends to decrease during late grand growth and maturation phases of sugarcane (Gascho and Shih 1983).

However, water availability affects the rate of $P_{n}$. Gascho and Shih (1983) recorded that positive $P_{n}$ occurs in leaves of sugarcane at or below the wilting point. However, the amount of $P_{n}$ was much less than in plants with an adequate water supply. Moreover, Roberts et al. (1990) revealed that $P_{n}, g_{s}$ and leaf extension growth of sugarcane were very low under rainfed conditions particularly during dry periods. However, differences in $P_{n}$ and $g_{s}$ between well watered and water stressed was not established early enough under stress and were not as consistent as for cell extension growth. Moreover, he pointed out that the effect of rainfall and recovery of $P_{n}, g_{s}$ and leaf extension growth occurred rapidly in rainfed cane except in cases where cane had only senescing leaves. All the above physiological variables showed a greater level of activity than was observed in cane receiving regular irrigation.

The behaviour of $g_{s}$ is in many respects was similar to the responses seen in $P_{n}$. The $g_{s}$ responds to the onset of stress at about the same value of water stress as $P_{n}$ and after prolonged stress very low $g_{s}$ are observed. Maximum values of $g_{s}$ of around $400 \mathrm{mmol} \mathrm{m}^{-2} \mathrm{~s}^{-1}$ were observed on well irrigated cane, in full radiation but with only moderate vapour pressure deficit (Roberts et al. 1990 and Grantz et al. 1987). Therefore, measurements of $g_{s}$ made directly by porometers could be used as a means of selecting drought tolerant varieties (Roberts et al. 1990). This could apply to varieties which conserve water by stomatal closure or alternatively maintain a high $g_{s}$ and moderate leaf water potential by more efficient or deeper rooting patterns. Bull and Glasziou (1975) recorded that in all cases investigated any reduction in $P_{n}$ was accompanied by increased stomatal resistance. Moreover, the decrease of $P_{n}$ in sugarcane under water stress was caused by both stomatal and non-stomatal fac-

\footnotetext{
*Corresponding author:chandrajithdesilva@yahoo.com

Paper presented at the 2nd National Symposium, Faculty of Agriculture, University of Ruhuna
} 
tors, initially mainly by stomatal closure, followed by non-stomatal factors as stress became severe (Du et al. 1996). Therefore, the objective of this study was to evaluate the stomatal limitation of $P_{n}$ in commercial sugarcane varieties in Sri Lanka and thereby identifying high yielding varieties under well watered and water stressed conditions and as well as drought tolerant traits of sugarcane which could be used for the hybridization programme to produce better hybrids of sugarcane for different sugarcane growing environments in Sri Lanka.

\section{METHODOLOGY}

A field experiment was conducted at the Sugarcane Research Institute $(S R I)$, Uda Walawe $\left(6^{\circ} 21^{\prime} \mathrm{N}\right.$ latitude, $80^{\circ} 48^{\prime} \mathrm{E}$ longitude and $76 \mathrm{~m}$ altitude) where the annual average rainfall is about $1450 \mathrm{~mm}$ with a distinctly bimodal distribution (Panabokke 1996). The mean annual temperature ranges from $22^{\circ} \mathrm{C}$ $32^{\circ} \mathrm{C}$. The average evaporation from a free water surface is about $5 \mathrm{~mm}$ per day (Sanmuganathan 1992). The soil has been classified as Ranna series of Reddish Brown Earth (RBE), great group of Rhodustalfs (order Alfisols, suborder Ustalfa), sandy clay loam texture (De Alwis and Panabokke 1972; Anon 1975), and moderately well drained with a $\mathrm{pH}$ of $6.5-6.7$. The bulk density of the soil ranges from $1.59-1.85 \mathrm{gcm}^{-3}$ (Sithakaran 1987). The respective soil water contents at saturation, field capacity and permanent wilting point are $30 \%$, $20 \% \quad(10 \mathrm{kPa})$ and $8 \%(1500 \mathrm{kPa})$, respectively (Sanmuganathan 1992).

The experiment was conducted as a two-factor factorial with 16 treatment combinations, composed of two main plot treatments as 'irrigated' ('wellwatered') and 'rainfed' ('water-stressed') and eight commercial sugarcane (Saccharum hybrid L.) varieties (i.e. SL7103, SL7130, SL8306, SL8613, SL88116, SLI121, M438/59 and Co775) as subplot treatments, in a split plot design. The irrigated treatment received $2 \mathrm{~m}^{3}$ of water per irrigation at 5-10 day intervals to maintain the soil water potential in the top $1 \mathrm{~m}$ above $-0.05 \mathrm{MPa}$. One meter deep trenches were made between irrigated and rainfed plots to avoid the lateral movement of water. Each treatment combination was replicated thrice. Plot size was $9 \mathrm{~m} \times 8.22 \mathrm{~m}$, containing 6 furrows at $1.37 \mathrm{~m}$ spacing. The sugarcane was planted and maintained under recommended procedures (Anon 1991).

Stomatal conductance $\left(g_{s}\right)$ and instantaneous transpiration rate $\left(E_{l}\right)$ per unit leaf area were measured in leaves of top, middle and bottom parts of the canopy layers using a steady-state porometer (LI-1600, LI-COR, Inc. LTD., Lincoln, USA) at 6 and 9 months after planting $(M A P)$. The measure- ments were done between 09:30 and 14:30h. Canopy stomatal conductance $\left(g_{c}\right)$ and instantaneous canopy transpiration rate $\left(E_{c}\right)$ were computed by summing the products of mean leaf $g_{s}$ and partial leaf area index in the three canopy layers (Squire and Black 1981).

Gas exchange studies were carried out using a portable photosynthetic system (LI -6400 and LI 6200, LI-COR, Inc. LTD., Lincoln, Nebraska, U.S.A.) comprising a LI 6200 gas analyser with a LI 6250 computer software. The apparatus was calibrated prior to measurements as described by Welles (1986). Leaf chamber in one litre capacity was adjusted to expose an area of $20 \mathrm{~cm}^{2}$ of the leaf. Atmospheric air was drawn into the system, by keeping the leaf chamber open. Then, a portion of sugarcane leaf was clamped into the leaf chamber. Measurements were taken when a steady decline in $\mathrm{CO}_{2}$ concentration in the chamber was observed. $\mathrm{CO}_{2}$ assimilation rate, stomatal conductance, transpiration rate, internal leaf $\mathrm{CO}_{2}$ concentration, air $\mathrm{CO}_{2}$ concentration and photosynthetically active radiation $(P A R)$ were monitored. The relative humidity ( $\mathrm{RH} \%)$ of the system was maintained at $65-$ $70 \%$ during the measurement by adjusting the air flow rate through the magnesium perchlorate desiccant.

Measurements were taken at $6 M A P, 8 M A P$ and $11 M A P$ on six days and two sessions per day. Photosynthetic $\left(\mathrm{CO}_{2}\right.$ assimilation) rate in all the leaves from top to bottom of the stalk in each variety was measured to identify the potential photosynthetic capacity and effective and ineffective leaves in the stalk. Transpiration efficiency $\left(P_{n} / E_{l}\right)$ of each and every experimental plot was calculated as the ratio between instantaneous photosynthetic rate $\left(P_{n}\right)$ and transpiration rate $\left(E_{l}\right)$ to determine the efficiency of water transpire through the stomata while photosynthesizing.

Significance of treatment differences was tested by analysis of variance $(A N O V A)$. Means were separated by the least significant difference $(L S D)$. Correlations between variables were determined by simple linear correlation analysis. The $S A S$ statistical computer package was used to analyse the data.

\section{RESULTS AND DISCUSSION}

\section{Impacts of variation in water regimes on stomatal conductance and transpiration}

There were significant water regime $\mathrm{x}$ variety interaction effects on stomatal conductance and instantaneous transpiration rate in terms of both individual leaves in the top leaf layer $\left(g_{s}\right.$, $\left.E_{l}\right)$ and the whole canopy $\left(g_{c}, E_{c}\right)$. Measurements taken from 159 and $167 D A P$ in Septem- 
Table 1 Mean stomatal conductance $\left(g_{s}\right)$ and instantaneous transpiration rate $\left(E_{l}\right) \pm$ standard error per unit leaf area at 159 and $167 D A P$ in different sugarcane varieties under irrigated and rainfed conditions.

\begin{tabular}{lllll}
\hline \multirow{2}{*}{ Variety } & \multicolumn{2}{c}{$\boldsymbol{g}_{\boldsymbol{s}}\left(\mathbf{c m ~ s}^{-\mathbf{1}}\right)$} & & \multicolumn{2}{l}{$\boldsymbol{E}_{\boldsymbol{l}}\left(\boldsymbol{\mu g} \mathbf{~ c m}^{-\mathbf{2}}\right.$ [leaf area] $\left.\mathbf{~}^{-1}\right)$} \\
\hline Irrigated & Rainfed & Irrigated & Rainfed \\
\hline SL88116 & $0.299 \pm 0.03$ & $0.119 \pm 0.02$ & $6.062 \pm 0.36$ & $2.185 \pm 0.27$ \\
Co775 & $0.225 \pm 0.02$ & $0.117 \pm 0.03$ & $4.298 \pm 0.14$ & $2.068 \pm 0.30$ \\
SL8306 & $0.233 \pm 0.02$ & $0.068 \pm 0.01$ & $4.508 \pm 0.23$ & $1.374 \pm 0.19$ \\
SL8613 & $0.188 \pm 0.02$ & $0.079 \pm 0.02$ & $3.699 \pm 0.25$ & $1.454 \pm 0.22$ \\
SL7130 & $0.243 \pm 0.02$ & $0.064 \pm 0.02$ & $4.488 \pm 0.23$ & $1.381 \pm 0.20$ \\
M438/59 & $0.212 \pm 0.02$ & $0.072 \pm 0.01$ & $4.601 \pm 0.33$ & $1.527 \pm 0.22$ \\
SL7103 & $0.233 \pm 0.02$ & $0.063 \pm 0.01$ & $4.854 \pm 0.43$ & $1.401 \pm 0.26$ \\
SLI121 & $0.294 \pm 0.04$ & $0.064 \pm 0.01$ & $5.608 \pm 0.56$ & $1.442 \pm 0.21$ \\
Mean & $0.241 \pm 0.01$ & $0.081 \pm 0.01$ & $4.765 \pm 0.13$ & $1.604 \pm 0.09$ \\
$L S D_{v}$ & 0.067 & 0.044 & 0.955 & 0.663 \\
$L S D_{w}$ & 0.013 & & 0.233 & \\
\hline
\end{tabular}

Note: $L S D_{v}=L S D(\mathrm{p}=0.05)$ for varietal comparisons within a water regime; $L S D_{w}=L S D(\mathrm{p}=0.05)$ for comparison of mean values between water regimes.

ber 2002, which fell within the period when the crops were experiencing a prolonged and continuous soil moisture depletion, showed the significant varietal variation of $g_{s}$ and $E_{l}$ within and between water regimes (Table 1). Moreover, soil water deficits significantly $(\mathrm{p}<0.001)$ reduced $g_{s}$ and $E_{l}$ in all varieties tested during prolonged and continuous soil moisture depletion from 159 and $167 D A P$. It reduced the average $g_{s}$ to the lowest value of $0.8 \mathrm{~mm} \mathrm{~s}^{-1}$, which confirmed the findings of Inman-Bamber and De Jager (1986) that the $g_{s}$ of sugarcane reached a minimum of about 0.5 to $1.0 \mathrm{~mm} \mathrm{~s}^{-1}$ when midday leaf water potential decreased by about -1.3 to $-17 \mathrm{MPa}$ at different water stress cycles. In the present study, the lowest $g_{s}$ and $E_{l}$ under rainfed conditions were observed in SL7103 and SL8306 respectively which conserving

Table 3 Canopy stomatal conductance $\left(g_{c}\right)$ and instantaneous canopy transpiration rate $\left(E_{c}\right) \pm$ standard error at $322 D A P$ in different sugarcane varieties under irrigated and rainfed conditions.

\begin{tabular}{lllll}
\hline \multirow{2}{*}{ Variety } & $\boldsymbol{g}_{\boldsymbol{c}}\left(\mathbf{c m ~ s}^{-1}\right)$ & & \multicolumn{2}{c}{$\boldsymbol{E}_{\boldsymbol{c}}\left(\boldsymbol{\mu g} \mathbf{~ c m}^{-2}\right.$ [land area] s} \\
\cline { 2 - 5 } & Irrigated & Rainfed & Irrigated & Rainfed \\
\hline SL88116 & $1.251 \pm 0.35$ & $0.279 \pm 0.06$ & $37.93 \pm 8.70$ & $10.25 \pm 3.82$ \\
Co775 & $0.941 \pm 0.19$ & $0.344 \pm 0.10$ & $32.53 \pm 9.26$ & $9.78 \pm 2.15$ \\
SL8306 & $0.899 \pm 0.14$ & $0.420 \pm 0.07$ & $31.19 \pm 5.50$ & $12.28 \pm 1.74$ \\
SL8613 & $0.719 \pm 0.44$ & $0.500 \pm 0.11$ & $18.49 \pm 10.62$ & $15.79 \pm 3.39$ \\
SL7130 & $0.559 \pm 0.17$ & $0.669 \pm 0.12$ & $14.04 \pm 3.92$ & $22.65 \pm 7.75$ \\
M438/59 & $0.624 \pm 0.11$ & $0.328 \pm 0.07$ & $17.41 \pm 2.70$ & $7.59 \pm 1.29$ \\
SL7103 & $0.704 \pm 0.14$ & $0.296 \pm 0.05$ & $18.40 \pm 3.76$ & $7.75 \pm 0.94$ \\
SLI121 & $1.090 \pm 0.35$ & $0.349 \pm 0.10$ & $34.93 \pm 7.56$ & $8.32 \pm 2.55$ \\
Mean & 0.838 & 0.386 & 25.21 & 11.33 \\
$L S D_{v}$ & 0.673 & 0.256 & 19.743 & 8.620 \\
$L S D_{w}$ & 0.189 & & 5.379 & \\
\hline
\end{tabular}

Note: $L S D_{v}=L S D(\mathrm{p}=0.05)$ for varietal comparisons within a water regime; $L S D_{w}=L S D(\mathrm{p}=0.05)$ for comparison of mean values between water regimes.
Table 2 Mean stomatal conductance $\left(g_{s}\right)$ and instantaneous transpiration rate of top leaves $\left(E_{l}\right) \pm$ standard error at $322 \mathrm{DAP}$ in different sugarcane varieties under irrigated and rainfed conditions.

\begin{tabular}{|c|c|c|c|c|}
\hline \multirow[t]{2}{*}{ Variety } & \multicolumn{2}{|c|}{$\begin{array}{l}\text { Mean stomatal conductance } \\
\text { of top leaves, } g_{s},\left(\mathrm{~cm} \mathrm{~s}^{-1}\right)\end{array}$} & \multicolumn{2}{|c|}{$\begin{array}{l}\text { Instantaneous transpira- } \\
\text { tion rate of top leaves, } E_{l} \text {, } \\
\left(\mu \mathrm{g} \mathrm{cm}^{-2} \text { [leaf area] s } \mathrm{s}^{-1}\right)\end{array}$} \\
\hline & Irrigated & Rainfed & Irrigated & Rainfed \\
\hline$\overline{\text { SL88116 }}$ & $0.195 \pm 0.06$ & $0.069 \pm 0.01$ & $6.163 \pm 1.16$ & $1.798 \pm 0.31$ \\
\hline Co775 & $0.142 \pm 0.04$ & $0.057 \pm 0.01$ & $5.028 \pm 1.70$ & $1.765 \pm 0.41$ \\
\hline SL8306 & $0.173 \pm 0.02$ & $0.103 \pm 0.02$ & $4.387 \pm 1.10$ & $3.498 \pm 0.11$ \\
\hline SL8613 & $0.079 \pm 0.03$ & $0.108 \pm 0.03$ & $2.793 \pm 0.66$ & $3.912 \pm 0.10$ \\
\hline SL7130 & $0.072 \pm 0.01$ & $0.132 \pm 0.02$ & $1.792 \pm 0.13$ & $4.588 \pm 1.29$ \\
\hline M438/59 & $0.177 \pm 0.01$ & $0.095 \pm 0.02$ & $4.178 \pm 0.18$ & $1.992 \pm 0.21$ \\
\hline SL7103 & $0.172 \pm 0.04$ & $0.077 \pm 0.02$ & $4.647 \pm 0.88$ & $2.183 \pm 0.52$ \\
\hline SLI121 & $0.147 \pm 0.03$ & $0.112 \pm 0.03$ & $4.457 \pm 0.68$ & $2.613 \pm 0.76$ \\
\hline Mean & 0.145 & 0.094 & 4.181 & 2.794 \\
\hline$L S D_{v}$ & 0.100 & 0.060 & 2.706 & 1.885 \\
\hline$L S D_{w}$ & 0.028 & & 0.814 & \\
\hline
\end{tabular}

Note: $L S D_{v}=L S D(\mathrm{p}=0.05)$ for varietal comparisons within a water regime; $L S D_{w}=L S D(\mathrm{p}=0.05)$ for comparison of mean values between water regimes.

moisture during the drought. The variety SL88116 which had the highest biomass production showed the highest $g_{s}$ and $E_{l}$ under both irrigated and rainfed conditions (Table 1).

Measurements taken at $322 D A P$ during the short dry spell in February 2003 after the Maha season rainfall, show the varietal variation on $g_{s}, E_{l}, g_{c}$ and $E_{c}$ within and between water regimes and the interaction effect of water regime $\mathrm{x}$ variety (Tables 2 and 3). Moreover, at $322 D A P$, soil water deficit significantly reduced $g_{s}, E_{l}, g_{c}$ and $E_{c}$ in a majority of varieties. Notably, SL8613 and SL7130 showed significantly greater $g_{s}$ and $E_{l}$ under rainfed conditions. The variety SL88116 which had the highest biomass production under both conditions (De Silva 2007) showed the highest $g_{s}, E_{l}, g_{c}$ and $E_{c}$ under

Table 4 Mean net photosynthetic rate $\left(P_{n}\right)$ and stomatal conductance $\left(g_{s}\right) \pm$ standard error of all leaves in the canopy during the period from $180-183 \mathrm{DAP}$ in different sugarcane varieties under irrigated and rainfed conditions.

\begin{tabular}{lllll}
\hline \multirow{2}{*}{ Variety } & \multicolumn{2}{l}{$\boldsymbol{P}_{\boldsymbol{n}}\left(\boldsymbol{\mu m o l ~ \mathbf { ~ m } ^ { - 2 } \mathbf { s } ^ { - 1 } )}\right.$} & \multicolumn{2}{l}{$\boldsymbol{g}_{\boldsymbol{s}}\left(\mathrm{mol} \mathrm{m}^{-2} \mathbf{s}^{-1}\right)$} \\
\cline { 2 - 5 } & Irrigated & Rainfed & Irrigated & Rainfed \\
\hline SL88116 & $24.7 \pm 3.1$ & $16.7 \pm 2.5$ & $0.775 \pm 0.12$ & $0.541 \pm 0.10$ \\
Co775 & $26.5 \pm 4.4$ & $20.9 \pm 2.5$ & $0.639 \pm 0.08$ & $0.407 \pm 0.03$ \\
SL8306 & $28.1 \pm 3.4$ & $27.3 \pm 2.0$ & $0.726 \pm 0.06$ & $0.373 \pm 0.03$ \\
SL8613 & $25.1 \pm 3.2$ & $15.5 \pm 2.2$ & $0.783 \pm 0.15$ & $0.378 \pm 0.03$ \\
SL7130 & $26.0 \pm 3.9$ & $21.1 \pm 3.1$ & $0.531 \pm 0.06$ & $0.370 \pm 0.03$ \\
M438/59 & $27.2 \pm 3.4$ & $10.4 \pm 1.9$ & $0.763 \pm 0.11$ & $0.336 \pm 0.02$ \\
SL7103 & $25.5 \pm 2.7$ & $15.2 \pm 2.4$ & $0.695 \pm 0.07$ & $0.428 \pm 0.05$ \\
SLI121 & $23.0 \pm 5.3$ & $17.2 \pm 3.4$ & $0.490 \pm 0.12$ & $0.329 \pm 0.07$ \\
Mean & 26.0 & 18.1 & 0.69 & 0.40 \\
LSD $D_{w}$ & 2.90 & & 0.06 & \\
\hline
\end{tabular}

Note: $L S D_{w}=L S D(\mathrm{p}=0.05)$ for comparison of mean values between water regimes. 
irrigated conditions and the lowest $g_{c}$ and the second lowest $g_{s}$ and $E_{l}$ under rainfed conditions. The variety Co775 which had second highest biomass production under both conditions recorded lowest $g_{s}$ and $E_{l}$ under rainfed conditions whereas lowest $E_{c}$ was recorded in M438/59. SL7103 observed second lowest $g_{c}$ and $E_{c}$ under rainfed conditions (Table 2 and 3).

When yields under both water regimes were considered, cane yield of this experiment showed significant positive correlations with $g_{s}(\mathrm{r}=0.49$ with $\mathrm{p}=0.05), E_{l}(\mathrm{r}=0.51$ with $\mathrm{p}=0.04), g_{c}(\mathrm{r}=0.80$ with $\mathrm{p}=0.0002)$ and $E_{c}(\mathrm{r}=0.74$ with $\mathrm{p}=0.0001)$. This indicated that greater stomatal opening and efficient water use are pre-requisites for increasing overall sugarcane yields in this environment. On the other hand, cane yield under rainfed conditions showed moderate negative correlations with $g_{s}(\mathrm{r}=$ -0.53 with $\mathrm{p}=0.18), \mathrm{El}(\mathrm{r}=-0.30$ with $\mathrm{p}=0.47)$ and $g_{c}(\mathrm{r}=-0.22$ with $\mathrm{p}=0.60)$. This indicated that water conservation mechanisms (i.e. lowering of $g_{s}$ and El) are needed in a variety to achieve higher yields under rainfed conditions. For example, the variety SL88116 which showed the highest rainfed cane yield had the second lowest $g_{s}$ and $\mathrm{El}$ and lowest $g_{c}$ under rainfed conditions at $322 D A P$. Conversely, SL8613 which had the lowest rainfed cane yield had the second highest $E_{l}, g_{c}$ and $E_{c}$ under rainfed conditions. Moreover, the present study confirmed that water conservation under drought conditions is of major importance in obtaining a satisfactory yield of sugarcane (De Silva 2007). As drought is common in many sugarcane growing areas and irrigation is often not possible, it is important to con-

Table 5 Mean net photosynthetic rate $\left(P_{n}\right)$, instantaneous transpiration rate $\left(E_{l}\right)$ and transpiration efficiency $\left(P_{n} / E_{l}\right) \pm$ standard error at $256 D A P$ in different sugarcane varieties under irrigated and rainfed conditions.

\begin{tabular}{lllllll}
\hline \multirow{2}{*}{ Variety } & \multicolumn{2}{l}{$\boldsymbol{P}_{n}\left(\mu \mathrm{mol} \mathrm{CO}_{2} \mathbf{m}^{-2} \mathbf{s}^{-1}\right)$} & $E_{l}\left(\mathbf{m o l} \mathrm{H}_{2} \mathrm{O} \mathrm{m}^{-2} \mathbf{s}^{-1}\right)$ & \multicolumn{2}{l}{$\boldsymbol{P}_{n} / \boldsymbol{E}_{l}\left(\mu \mathrm{mol} \mathrm{CO}_{2} \mathbf{m o l}^{-1}\right.$} \\
\cline { 2 - 7 } & Irrigated & Rainfed & Irrigated & Rainfed & Irrigated & Rainfed \\
\hline SL88116 & $22.4 \pm 3.4$ & $20.4 \pm 0.5$ & $1.8 \pm 0.3$ & $2.4 \pm 0.1$ & $12.3 \pm 0.2$ & $8.7 \pm 0.4$ \\
Co775 & $28.3 \pm 2.7$ & $21.7 \pm 0.5$ & $3.3 \pm 0.1$ & $1.8 \pm 0.3$ & $8.6 \pm 0.6$ & $13.4 \pm 2.9$ \\
SL8306 & $17.9 \pm 1.5$ & $24.2 \pm 1.3$ & $1.9 \pm 0.0$ & $2.1 \pm 0.2$ & $9.6 \pm 1.0$ & $11.7 \pm 0.5$ \\
SL8613 & $8.4 \pm 1.5$ & $23.3 \pm 1.4$ & $0.9 \pm 0.0$ & $2.5 \pm 0.1$ & $9.6 \pm 1.6$ & $9.1 \pm 0.2$ \\
SL7130 & $17.5 \pm 0.8$ & $28.4 \pm 0.6$ & $1.4 \pm 0.4$ & $2.4 \pm 0.1$ & $14.0 \pm 4.0$ & $12.0 \pm 0.7$ \\
M438/59 & $12.0 \pm 0.9$ & $27.6 \pm 0.3$ & $0.8 \pm 0.1$ & $3.2 \pm 0.1$ & $16.5 \pm 3.0$ & $8.5 \pm 0.3$ \\
SL7103 & $21.1 \pm 1.8$ & $23.8 \pm 1.7$ & $1.5 \pm 0.3$ & $2.6 \pm 0.0$ & $15.2 \pm 2.4$ & $9.0 \pm 0.6$ \\
SL121 & $18.7 \pm 3.1$ & $26.9 \pm 0.7$ & $2.2 \pm 0.3$ & $2.7 \pm 0.1$ & $8.4 \pm 1.2$ & $10.0 \pm 0.6$ \\
Mean & $18.3 \pm 1.3$ & $24.5 \pm 0.6$ & $1.7 \pm 0.2$ & $2.5 \pm 0.1$ & $11.8 \pm 0.9$ & $10.3 \pm 0.5$ \\
$L S D_{v}$ & 6.0 & 3.0 & 0.6 & 0.4 & 6.1 & 3.3 \\
$L S D_{w}$ & 1.7 & & 0.2 & & 1.7 & \\
\hline
\end{tabular}

Note: $L S D_{v}=L S D(\mathrm{p}=0.05)$ for varietal comparisons within a water regime; $L S D_{w}=L S D(\mathrm{p}=0.05)$ for comparison of mean values between water regimes. sider reducing transpiration and thereby reducing consumptive water use.

Impacts of variation in water regimes on stomatal conductance, transpiration and photosynthesis

During prolong dry period from $180-183 D A P$, soil water deficits significantly $(\mathrm{p}<0.05)$ reduced $P_{n}$ and $g_{s}$ in all varieties tested except in SL8306 (Table 4). The behaviour of $g_{s}$ in majority of tested varieties was similar to the responses seen in $P_{n}$. However, SL8306 recorded the highest $P_{n}$ under both water regimes and the lowest reduction of $P_{n}$ due to water stress among all varieties tested under rainfed conditions. SL88116 had the second highest and the highest $g_{s}$ within the irrigated and rainfed regimes respectively. The $P_{n}$ varied among tested varieties from $23-28 \mu \mathrm{mol} \mathrm{m} \mathrm{m}^{-2}$ and $10-27 \mu \mathrm{mol} \mathrm{m} \mathrm{m}^{-2} \mathrm{~s}^{-1}$ under irrigated and rainfed conditions respectively (Table 4).

At $256 D A P, P_{n} / E_{l}$ showed significant varietal variation under rainfed conditions and water regime $\mathrm{x}$ variety interaction (Table 5). Both at $256 D A P$ (during the Maha season rainfall) and at $340 D A P$ [(end of the Maha season rainfall) (late grand growth and maturation stages)], a majority of varieties tested recorded greater $P_{n}, E_{l}$ and $g_{s}$, and lower $P_{n} / E_{l}$ under rainfed conditions than irrigated conditions with the few exceptions (Tables 5 and 6). The difference in these variables between irrigated and rainfed conditions at these stages are due to the different developmental stages of the crops in spite of differential water availability under the two conditions. Because of the delayed development of the rainfed crops (De Silva and De Costa 2004 and De

Table 6 Mean net photosynthetic rate $\left(P_{n}\right)$, instantaneous transpiration rate $\left(E_{l}\right)$ and transpiration efficiency $\left(P_{n} / E_{l}\right) \pm$ standard error at $340 \mathrm{DAP}$ in different sugarcane varieties under irrigated and rainfed conditions.

\begin{tabular}{|c|c|c|c|c|c|c|}
\hline \multirow[t]{2}{*}{ Variety } & \multicolumn{2}{|c|}{$P_{n}\left(\mu \mathrm{mol} \mathrm{CO}_{2} \mathrm{~m}^{-2} \mathrm{~s}^{-1}\right)$} & \multicolumn{2}{|c|}{$E_{l}\left(\mathrm{~mol} \mathrm{H}_{2} O \mathrm{~m}^{-2} \mathrm{~s}^{-1}\right)$} & \multicolumn{2}{|c|}{$\begin{array}{l}P_{n} / E_{l}\left(\mu \mathrm{mol} \mathrm{CO}_{2} \mathrm{~mol}^{-}\right. \\
\left.{ }^{1} \mathrm{H}_{2} \mathrm{O} \text { transpired }\right)\end{array}$} \\
\hline & Irrigated & Rainfed & Irrigated & Rainfed & Irrigated & Rainfed \\
\hline$\overline{\text { SL88116 }}$ & $21.2 \pm 2.3$ & $32.0 \pm 2.2$ & $4.3 \pm 0.4$ & $5.8 \pm 0.1$ & $5.0 \pm 0.7$ & $5.5 \pm 0.5$ \\
\hline Co775 & $29.5 \pm 1.1$ & $22.8 \pm 1.6$ & $5.0 \pm 0.4$ & $4.5 \pm 0.6$ & $5.9 \pm 0.3$ & $5.1 \pm 0.3$ \\
\hline SL8306 & $21.4 \pm 0.3$ & $29.3 \pm 1.3$ & $4.3 \pm 0.1$ & $5.8 \pm 0.1$ & $5.0 \pm 0.1$ & $5.1 \pm 0.2$ \\
\hline SL8613 & $17.8 \pm 0.6$ & $27.2 \pm 3.5$ & $3.2 \pm 0.1$ & $5.6 \pm 0.6$ & $5.5 \pm 0.3$ & $4.9 \pm 0.1$ \\
\hline SL7130 & $15.0 \pm 2.8$ & $30.4 \pm 0.9$ & $3.5 \pm 0.4$ & $5.7 \pm 0.2$ & $4.2 \pm 0.3$ & $5.4 \pm 0.3$ \\
\hline M438/59 & $19.0 \pm 1.2$ & $22.9 \pm 2.3$ & $3.6 \pm 0.3$ & $4.4 \pm 0.4$ & $5.3 \pm 0.1$ & $5.2 \pm 0.5$ \\
\hline SL7103 & $22.0 \pm 2.3$ & $14.2 \pm 1.6$ & $4.3 \pm 0.2$ & $3.1 \pm 0.1$ & $5.2 \pm 0.8$ & $4.5 \pm 0.4$ \\
\hline SLI121 & $17.9 \pm 1.2$ & $27.3 \pm 2.7$ & $4.3 \pm 0.2$ & $5.0 \pm 0.4$ & $4.2 \pm 0.5$ & $5.4 \pm 0.1$ \\
\hline Mean & $20.5 \pm 1.0$ & $25.8 \pm 1.3$ & $4.1 \pm 0.1$ & $5.0 \pm 0.2$ & $5.0 \pm 0.2$ & $5.1 \pm 0.1$ \\
\hline$L S D_{v}$ & 5.1 & 6.9 & 0.8 & 1.2 & 1.4 & 1.0 \\
\hline$L S D_{w}$ & 2.0 & & 0.4 & & 0.4 & \\
\hline
\end{tabular}

Note: $L S D_{v}=L S D(\mathrm{p}=0.05)$ for varietal comparisons within a water regime; $L S D_{w}=L S D(\mathrm{p}=0.05)$ for comparison of mean values between water regimes. 
Silva 2007), at the time of measuring photosynthesis, leaves of the rainfed crop were probably at a more metabolically active stage than the leaves of the irrigated crop, which were near maturation. $P_{n}$ is at a maximum during the grand growth stage and tends to decrease during late grand growth and maturation phases (Gascho and Shih 1983).

In agreement with current findings, Roberts et al. (1990) pointed out that the effect of the rainfall and recovery of all above physiological variables show a greater level of activity under rainfed conditions than observed in cane receiving regular irrigation. In the present study, Co775 recorded the highest $P_{n}, E_{l}$ and $g_{s}$ both at 256 and $340 D A P$ and highest $P_{n} / E_{l}$ at $340 D A P$ under irrigated conditions whereas it had the lowest $g_{s}$ and $E_{1}$, and the highest $P_{n} / E_{l}$ under rainfed conditions at 256. At $340 D A P$; SL88116 recorded the highest $P_{n}, E_{l}, g_{s}$ and $P_{n} / E_{l}$ under rainfed conditions. The lowest $E_{1}$ and $g_{s}$ were observed in SL7103 under rainfed conditions. Moreover, varieties SL8306 (both at 256 and 340 $D A P$ ), Co775 (at $256 D A P$ ) and SL88116 (at 340 $D A P$ ) showed greater $P_{n} / E_{l}$ under rainfed conditions than irrigated conditions [(Tables 5 and 6) (Data of simultaneous measurements of $g_{s}$ at 256 and $340 D A P$ are not shown)].

Greater $P_{n} / E_{l}$ could be an important trait in drought resistant varieties. The $g_{s}$ is a key parameter that control both $P_{n}$ and $E_{l}$ because of the central position of stomata in the leaf gas exchange pathway (De Costa 2000). Sensitivity of stomata to water stress contributes to drought tolerance of a variety. More sensitive stomata could conserve more water until yield formation. Varieties with less sensitive stomata may be able to maintain $P_{n}$ at a higher rate and may produce a higher yield under intermittent drought but it does not persist for a long period (Ludlow and Muchow 1990). However, accurate determination of $P_{n}, E_{l}, g_{s}$ and $P_{n} / E_{l}$ under field conditions are difficult because it is difficult to impose a specific level of water stress on plants under open field conditions. Above variables in sugarcane respond quickly to unpredictable rainfall that occurs at any time during the dry spells as it is an indeterminate type long duration crop.

\section{CONCLUSIONS}

The study showed that there is adequate varietal variation in the evaluated physiological characters under the different growing conditions. Great differences existed between irrigated and rainfed conditions in the characters and varied significantly with the time and stage of crop growth. Therefore, it is required to evaluate above characters at varying levels of water stress on plants during grand growth stage in accurate determination of physiological response of determining yield and drought resistance. Among the eight varieties tested, there was no single variety in which all above characters performed at favourable levels under different conditions. Different characters were responsible for higher performances in different varieties under different conditions. Therefore, we recommend to use above characters which have shown significant correlations with cane yield under different conditions for hybridisation programmes to produce hybrids in which several characters are combined at favourable levels for different sugarcane growing conditions in Sri Lanka.

\section{ACKNOWLEDGEMENTS}

This research was funded by the Sugarcane Research Institute of Sri Lanka. The director and board of governors of Sugarcane Research Institute, the assistance given by the staff of the Sugarcane Research Institute, Department of Crop Science, Faculty of Agriculture, University of Peradeniya and Plant Science Department of Rubber Research Institute of Sri Lanka are gratefully acknowledged.

\section{REFERENCES}

Anon 1975 Soil taxonomy. A basic system of soil classification, United States Department of Agriculture Washington DC, USA. pp 753.

Anon 1991 Cultivation practices of sugarcane (in sinhala), advisory circular No. 1, Sugarcane Research Institute, Uda Walawa, Sri Lanka pp 2-13.

Bull TA and Glasziou KT 1975 Sugarcane. In: Crop Physiology: Some case histories, Evans L $\mathrm{T}$ (ed.), Cambridge University Press, London, UK. pp 51-72.

De Alwis KAN and Panabokke CR 1972 Handbook of the soils of Sri Lanka. J. Soil Sci. Soc. Sri Lanka 2: 1-26.

De Costa WAJM 2000 Principles of Crop Physiology: Towards an understanding of crop yield determination and improvement. University of Peradeniya, Sri Lanka. pp 123-129.

De Silva ALC and De Costa WAJM 2004 Varietal variation in growth, physiology and yield of sugarcane under two contrasting water regimes. Tropical Agric. Res. 16: 1-12.

De Silva ALC 2007 Investigation of growth, yield, ratooning ability and some important physiological attributes of a selected set of commercial sugarcane varieties in Sri Lanka under irrigated and rainfed conditions. Unpublished MPhil. thesis Postgraduate Institute of Agriculture, University of Peredeniya. 
Du Y-C, Kawamitsu Y, Nose A, Hiyane S, Murayama S, Wasano K and Uchida Y 1996 Effects of water stress on carbon exchange rate and activities of photosynthetic enzymes in leaves of sugarcane (Saccharum sp.). Aust. J. Plant Physiol. 23: 719-726.

Gascho GJ and Shih SF 1983 Sugarcane. In: Crop Water Relations, Teare ID and Peet MM (Eds.), John Wiley and Sons, USA. pp 445-477.

Grantz DA, Moore PH and Zeiger E 1987 Stomatal responses to light and humidity in sugarcane: prediction of daily time courses and identification of potential selection criteria. Plant Cell and Environment. 10: 197-204.

Inman-Bamber NG and De Jager JM 1986 The reaction of two varieties of sugarcane to water stress. Field Crops Res. 14: 15-28.

Irvine JE 1967 Photosynthesis of sugarcane varieties under field conditions. Crop Science. 7: 297-300.

Irvine JE 1975 Relations of photosynthetic rates and leaf canopy characters to sugarcane yield. Crop Science. 15: 671-676.

Irvine JE 1983 Sugarcane. In: Potential productivity of field crops under different environments. International Rice Research Institute, Los Banos, Philippines. pp. 361-381.

Ludlow MM and Muchow RC 1990 A Critical evaluation of traits for improving crop yield in water-limited environments. Advances in Agronomy 43: 107-153.
Panabokke CR 1996 Soils and Agroecological Environments of Sri Lanka. Natural Resources, Science and Energy Authority of Sri Lanka. pp. 73-100.

Roberts J, Nayamuth R A, Batchelor C H and Soopramanien G C 1990 Plant-water relations of sugarcane (Saccharum officinarum L.) under a range of irrigated treatments. Agricultural Water Management. 17: 95-115.

Sanmuganathan K 1992 Modeling growth of rainfed and irrigated sugarcane in the dry zone of Sri Lanka. Unpublished MPhil. thesis. University of Newcastle, UK. pp. 7-23.

Sithakaran VS 1987 Study of some physical properties of the research farm at Sugarcane Research Institute, UdaWalawa. Unpublished BSc research report, University of Peradeniya, Sri Lanka pp. 34-43.

Squire GR and Black CR 1981 Stomatal behaviour in the field. pp. 223-245 In: Jarvis PG and Mansfield TA (Eds.) Stomatal Physiology. Cambridge University Press, Cambridge.

Welles J 1986 A portable photosynthesis system. In advanced agricultural instrumentation. pp. 2138. 